\title{
Um iluminador de baixo custo para a realização de experimentos de óptica geométrica
}

\author{
A low cost light illuminator for geometrical optics experimentation
}

\author{
Gerson Kniphoff da Cruz $^{* 1}$, Marcos Aurélio Viatroski ${ }^{1}$, Maria Eugênia Meyer Levy ${ }^{1}$, Franciele \\ Nunes de Siqueira ${ }^{1}$, Sergio Leonardo Gomez ${ }^{1}$, Cláudia Bonardi ${ }^{1}$ \\ ${ }^{1}$ Universidade Estadual de Ponta Grossa, Departamento de Física, Ponta Grossa, PR, Brasil
}

\begin{abstract}
Recebido em 07 de Agosto, 2017. Revisado em 19 de Dezembro, 2017. Aceito em 22 de Dezembro, 2017.
\end{abstract}
\begin{abstract}
Uma justificativa apresentada para a pouca utilização dos experimentos de óptica geométrica nas escolas brasileiras é o elevado custo dos equipamentos necessários para tais estudos. Neste trabalho, descrevemos um iluminador de LEDs de baixo custo que apresenta uma alta performance quando comparado com os iluminadores comerciais para o estudo de lentes esféricas. Associando-se ao iluminador a lente de uma lupa, que pode ser adquirida em loja de materiais de escritório, é possível a conceituação completa da óptica geométrica de lentes esféricas. Como características do novo equipamento, ressalta-se a possibilidade de utilizá-lo em ambientes iluminados, a facilidade no estudo das caracterizações de imagens formadas em sistemas ópticos e a possibilidade de simulação de uma situação real de formação de uma imagem por uma lente. No trabalho, também são apresentados e discutidos exemplos de aplicações do iluminador. Experimentos básicos e fundamentais da óptica geométrica de lentes esféricas são colocados em evidência com este novo equipamento.
\end{abstract}

Palavras-chave: óptica geométrica; lentes esféricas, lupa.

\begin{abstract}
A justification presented for the low utilization of geometrical optics experiments in Brazilian schools is the high cost of the equipment required for such studies. In this work, we describe a low-cost LED illuminator that presents a high performance when compared to commercial illuminators for the study of spherical lenses. By associating with the illuminator the lens of a magnifying glass, which can be acquired in an office supply store, it is possible to fully conceptualize the geometrical optics of spherical lenses. Among the characteristics of the new equipment it is emphasized the possibility to use it in illuminated environments, the ease in the study of the characterizations of images formed in optical systems and the possibility of simulation of a real situation of formation of an image by a lens. Examples of applications using the illuminator are also presented and discussed. Basic and fundamental experiments on geometrical optics of spherical lenses are highlighted with this new equipment.
\end{abstract}

Keywords: spherical lens, magnifying glass.

\section{Introdução}

São inúmeras as dificuldades apresentadas pelos professores de ensino médio para não abordarem o tema óptica geométrica. Alguns dizem: "Não dá tempo! Com uma aula por semana, não dá para estudar toda a física". Outros afirmam discutir o tema, mas com pouca ênfase, porque o ano sempre está acabando quando se chega ao tema. Se essas questões existem para uma abordagem teórica, não é de se espantar a completa ausência das atividades experimentais. Entretanto, o que sabemos é que a óptica geométrica é uma porta de entrada para alunos de ensino médio e universitários terem acesso ao cerne da pesquisa científica de várias áreas da física e afins. Construir uma abordagem de óptica geométrica efetiva no ensino médio é fundamental para que tenhamos bons pesquisadores, seja pela excelente oportunidade de interagir plenamente com dispositivos ópticos, por criar

*Endereço de correspondência: gersonkc@gmail.com possibilidades de demonstrar princípios fundamentais da física, ou ainda, pelas oportunidades instigadoras que esse tema pode produzir [1-5]. Além do mais, é um tema importantíssimo porque faz parte de nosso dia-a-dia.

Kits de óptica geométrica são encontrados no mercado e apresentam-se sob diversas formas e compostos por diferentes componentes [6-13]. Especificamente para experimentos de reflexão e refração a implementação de fontes lasers facilitaram sobremaneira certas comprovações de leis físicas, no entanto, para o estudo especificamente de lentes esféricas nenhuma solução viável foi encontrada para dois problemas específicos: a necessidade do escurecimento do ambiente de trabalho em que os experimentos são realizados e a caracterização efetiva da imagem formada.

Em todos os casos, o objetivo dos iluminadores comercializados é o de produzir feixes de luz para serem utilizados nos bancos ópticos. No entanto, não é isso o que se vê no dia-a-dia. Quando observamos a imagem 
de um pedaço de papel com uma lupa, por exemplo, visualizamos a luz espalhada pelo papel para definirmos a sua imagem. Não há raios de luz como nos desenhos dos livros. Cada pedaço do papel reflete luz em todas as direções e somente a luz refletida pelo papel que cruzou através da lente será utilizada para produzir a imagem.

Nesse trabalho apresentamos uma solução simples e viável para essas questões mencionadas. Criamos um iluminador de baixo custo e de fácil elaboração, porém altamente desejável em épocas de escassos recursos financeiros. É um iluminador baseado na utilização de diodos emissores de luz ("LED - Light Emitting Diode") de alto brilho e que diferentemente dos iluminadores tradicionais, pode ser empregado em ambiente iluminado. O equipamento vem sendo utilizado com grande êxito há mais de oito anos em aulas experimentais de óptica geométrica dos cursos de engenharia e física da Universidade Estadual de Ponta Grossa.

\section{Lentes esféricas delgadas}

Uma lente é um dispositivo ótico formado a partir de duas superfícies refratoras sendo a lente mais simples aquela produzida a partir de duas superfícies refratoras esféricas de raios iguais (Figura 1). Numa lente esférica delgada essas duas superfícies estão bastante próximas uma da outra. Essa lente pode ser facilmente identificada porque ela possui sua borda, em toda a sua circunferência, mais fina do que o centro da lente.

Para esse tipo de lente raios incidentes paralelos ao eixo ótico convergem para um mesmo ponto (Figura 2a). Esse ponto é chamado de ponto focal e a distância medida deste ponto até o vértice da lente é nominada distância focal da lente ( f ). A distância focal é uma característica da lente. Se a fonte emissora de luz estiver posicionada no ponto focal, os raios divergentes a partir do ponto focal que incidirem sobre a lente serão redirecionados para a direção paralela ao eixo ótico da lente (Figura 2b). Devido a essas propriedades uma lente com essas características é chamada de lente convergente.

Uma lente convergente pode formar uma imagem de um objeto extenso. Em livros básicos de física encontramos a dedução da equação (1) que relaciona s (a distância medida da posição do objeto até o vértice da lente), s'

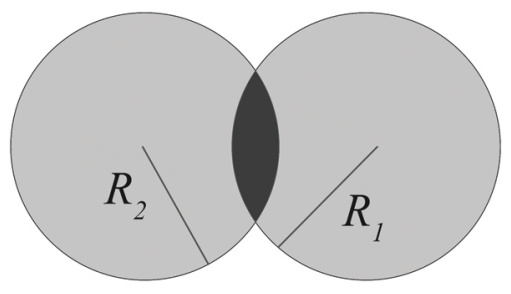

Figura 1: Um esquema mostrando o plano que contém o centro de duas esferas de raios $R_{1}$ e $R_{2}$. A lente esférica biconvexa é obtida a partir da região de interseção (região preta na figura) das duas esferas de materiais transparentes. (a distância medida da posição da imagem formada pela lente até o vértice da lente) e f (a distância focal da lente) (Veja Figura 3).

$$
\frac{1}{f}=\frac{1}{s}+\frac{1}{s^{\prime}}
$$

Na Figura 3 estão indicados três raios principais que podem ser utilizados para se encontrar a posição da imagem. Estão indicados: o raio que incide paralelamente ao eixo ótico e que é redirecionado pela lente para o foco; o raio que cruza pelo vértice da lente e que não sofre desvio; e o raio que passa pelo ponto focal e que é redirecionado pela lente paralelamente ao eixo ótico. A imagem é formada no ponto de cruzamento destes raios. Apenas dois destes são necessários para a indicação do ponto de formação da imagem.

A equação (2) apresenta a relação que mede a ampliação transversal $(\mathrm{m})$ da imagem formada pela lente delgada convergente, em relação às dimensões do objeto.

$$
m=-\frac{s^{\prime}}{s}
$$

\section{Descrição do iluminador}

Na Figura 4 temos um registro fotográfico do iluminador proposto neste trabalho. Na Figura 4a uma visão frontal do iluminador em que se vê um conjunto de LEDs de alta intensidade posicionados na forma de uma matriz $\mathrm{L}$ de $\mathrm{m}$ linhas por $\mathrm{n}$ colunas em que $\mathrm{m}=\mathrm{n}=3$. Ou seja, cada LED é um elemento de uma matriz 3 x 3 . Visto de frente, por exemplo, o LED central é o elemento $\mathrm{L}_{2,2}$, o LED superior esquerdo é o elemento $\mathrm{L}_{1,1}$, e assim por diante. É possível identificar também, que os LEDs possuem cores variadas. A escolha das cores dependerá da disponibilidade de cores no momento da elaboração do iluminador. O importante é que os três elementos da segunda linha sejam todos da mesma cor e que essa cor não seja utilizada para os demais elementos da matriz.

Na Figura 4b uma visão da parte traseira do iluminador. Nela se vê uma matriz $\mathrm{C}$ de 3 x 3 elementos em que cada elemento é uma chave liga/desliga que irá acionar individualmente cada LED diretamente a ela associado. Em outras palavras, estamos associando o elemento LED $\mathrm{L}_{3,1}$ ao elemento chave $\mathrm{C}_{3,1}$. É importante que a denominação dos elementos chaves seja feita a partir da visão frontal com o objetivo de evitar associações indevidas como por exemplo do elemento $\mathrm{L}_{1,1}$ com o elemento $\mathrm{C}_{1,3}$.

Uma dica fundamental para o desenvolvimento desse dispositivo é que a distribuição dos LED deve ser feita de acordo com a dimensão do diâmetro da lente que será utilizada nos trabalhos. Para isso deve-se calcular a distância entre os elementos LEDs da diagonal principal da matriz. No caso aqui apresentado a separação entre os LEDs foi definida em $15 \mathrm{~mm}$ centro-a-centro o que levaria a uma diagonal de aproximadamente $42,4 \mathrm{~mm}$. Utilizamos em nosso protótipo uma lente de $50 \mathrm{~mm}$ de diâmetro. A lente é facilmente obtida em lojas de 

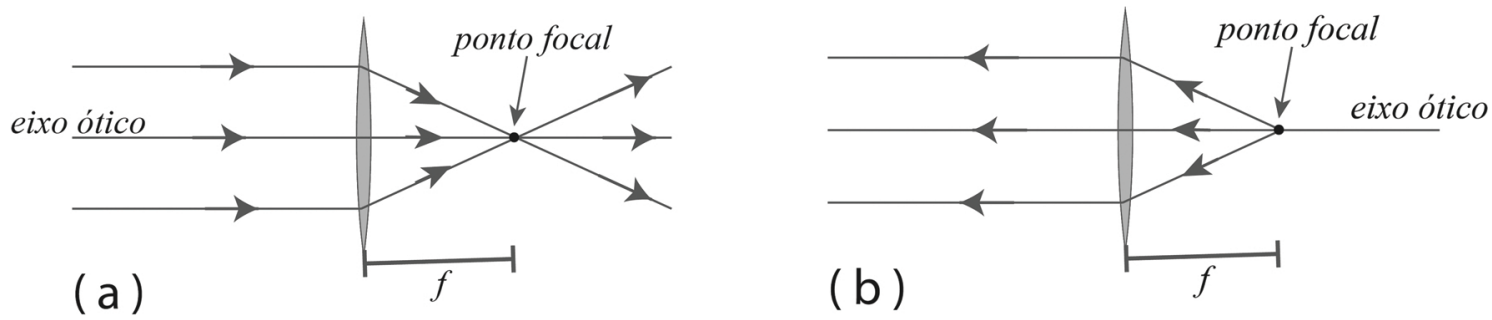

Figura 2: (a) Um esquema representativo para mostrar que raios incidentes numa lente esférica convergente delgada paralelos ao eixo ótico são desviados para um mesmo ponto, o foco. (b) Um esquema para mostrar que se uma fonte de luz estiver sobre o ponto focal, os raios emitidos que incidirem sobre a lente serão redirecionados paralelamente ao eixo ótico da lente.

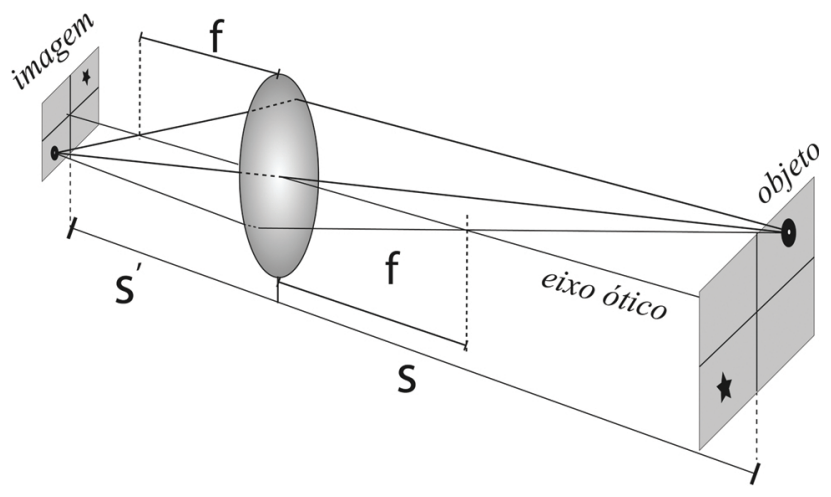

Figura 3: Um esquema representativo de um objeto em frente a uma lente esférica convergente delgada. Na situação esquematizada ( $s>2 f$ ) temos a formação de uma imagem real, invertida e de tamanho menor do que o objeto. s é a distância medida sobre o eixo ótico entre o plano do objeto extenso e o vértice da lente e s' é a distância medida sobre o eixo ótico entre o vértice da lente e o plano de formação da imagem extensa. f é a distância focal da lente. Na figura também estão representados três raios principais que podem ser utilizados para se encontrar a posição da imagem.

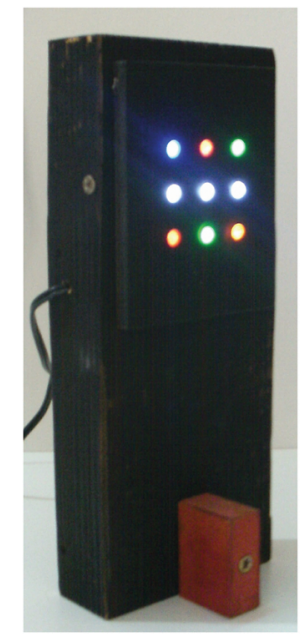

( a )

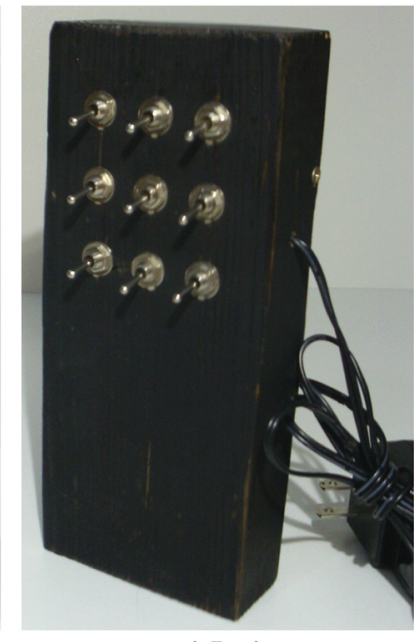

( b )
Figura 4: O iluminador visto de frente e verso. (a) frontalmente temos uma visualização dos LEDs que compõem o iluminador. (b) no verso vemos as chaves liga/desliga que acionam os LEDs correspondentes. matérias de escritório com o nome de lupa. Esse cuidado é fundamental para que o dispositivo possa ser utilizado nos experimentos como veremos adiante.

Para acionarmos os LEDs devemos considerar o circuito apresentado na Figura 5. Como fonte de alimentação utilizamos uma fonte de alimentação de um aparelho celular. Normalmente essas possuem tensões de entrada de $110 / 220 \mathrm{~V}$ e tensão de saída de $5,0 \mathrm{~V}$ com corrente de $500 \mathrm{~mA}$. Essas tensões são suficientes porque um LED é acionado com tensões normalmente na faixa de 2,0 - 3,0 $\mathrm{V}$ e com correntes de cerca de 20 - $30 \mathrm{~mA}$. Vale ressaltar que cada LED é acionado com uma tensão nominal e corrente específica de acordo com sua cor.

Cada ramo do circuito da Figura 5 é um circuito composto por uma chave LIG/DES (elemento $\mathrm{C}_{\mathrm{m}, \mathrm{n}}$ ), um LED (elemento $\left.L_{m, n}\right)$ e um resistor de proteção $\left(R_{m, n}\right)$ conectados em ligação série. Assim sendo, a tensão nos terminais do resistor será nominalmente igual à diferença de tensão entre a tensão da fonte $(\mathrm{V})$ e a tensão que aparecerá nos terminais do LED $\left(V_{L_{m, n}}\right)$. Essa constatação permite calcularmos o valor do resistor de proteção $R_{m, n}$

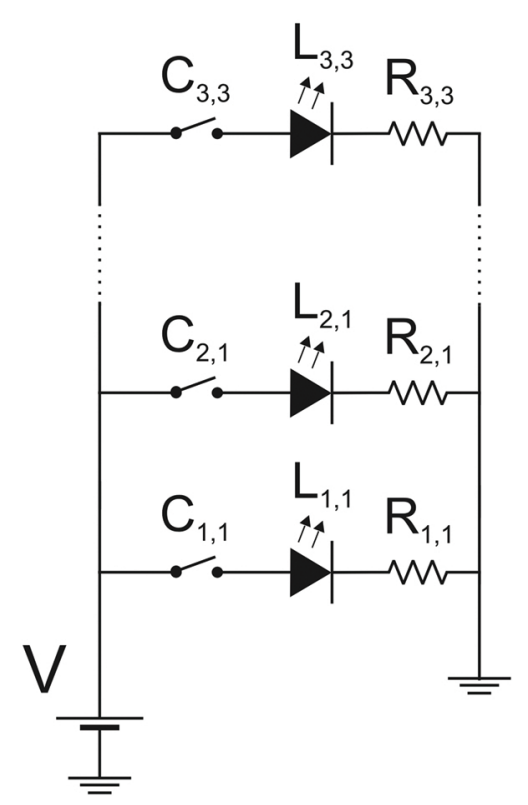

Figura 5: Uma representação do circuito acionador do iluminador. Cada ramo aciona individualmente um LED. 
através da equação (3):

$$
R_{m, n}=\frac{V-V_{L_{m, n}}}{I_{L_{m, n}}}
$$

Na equação (3), $V_{L_{m, n}}$ é a tensão de trabalho e $I_{L_{m, n}}$ é a corrente máxima do elemento LED $\mathrm{L}_{\mathrm{m}, \mathrm{n}}$. Como resultado temos um iluminador composto de uma matriz de LEDs que poderão ser individualmente acionados.

Para finalizarmos apresentamos o custo do iluminador. Os valores são referentes ao segundo semestre de 2017. São necessários: LEDs de alto brilho $5 \mathrm{~mm}$ (9 unidades $\mathrm{x} \mathrm{R} \$ 0,43$ /unidade $=\mathrm{R} \$ 3,87$; chaves alavanca duas posições $2 \mathrm{~T}$ lig/des (9 unidades x $\mathrm{R} \$ 2,48 /$ unidade $=$ $\mathrm{R} \$ 22,32$ ); fonte de alimentação (gratuita pois utiliza um carregador de celular em desuso); lente (lupa $50 \mathrm{~mm}-$ $\mathrm{R} \$ 18,18)$. Ou seja, de materiais totalizamos um montante de cerca de $\mathrm{R} \$ 44,37$ para a elaboração do conjunto ótico utilizado nesse trabalho.

\section{Utilização do iluminador}

Para demostrarmos como nosso iluminador auxilia no entendimento da óptica geométrica, vamos inicialmente estudar o próprio iluminador. Definiremos o eixo óptico, foco e o plano de imagem de uma lente convergente. Em seguida apresentaremos alguns experimentos básicos relativos às características das imagens formadas pela lente. Ao final, propomos como aplicação do iluminador uma atividade diferenciada para a determinação direta da distância focal de uma lente convergente.

\subsection{Plano de imagem $\mathrm{x}$ distância focal}

Como prática inicial vamos fazer um estudo do próprio iluminador para demonstrarmos como ele funciona. Para isso, vamos posicionar o iluminador a uma distância $\mathrm{X} \rightarrow$ $\infty$ de uma lente $\mathrm{L}$ convergente. Uma distância superior a $7 \mathrm{~m}$ é uma boa distância. Acionemos apenas o elemento $\mathrm{L}_{2,2}$, ou seja, o LED central. Para facilitar indicou-se o LED em amarelo na Figura 6. Analisemos a situação na seguinte ordem: (i) O LED emite luz em várias direções dentro de um ângulo indicado pelo fabricante (Figura 6a). (ii) O raio central (1) atravessa a lente sem ser desviado. Essa direção se prolongará ao infinito e será definida como o eixo óptico do sistema. (iii) Pergunta-se: O que ocorrerá com os raios exteriores identificados na Figura $6 \mathrm{~b}$ pelos números (2) e (3)? Nomina-se de raios exteriores porque são os raios que limitam o cone que define o fluxo luminoso que atravessará a lente. Lembrese que o trabalho aqui apresentado é de um sistema em três dimensões e não planificado como mostra a Figura 6.

Movendo-se o anteparo após a lente, verifica-se que em dada posição do anteparo, um ponto de luz é projetado sobre a superfície do anteparo. Esse ponto é a imagem do LED emissor formada pela lente L. A distância entre o vértice da lente $L$ e a imagem I'é identificada por s'.

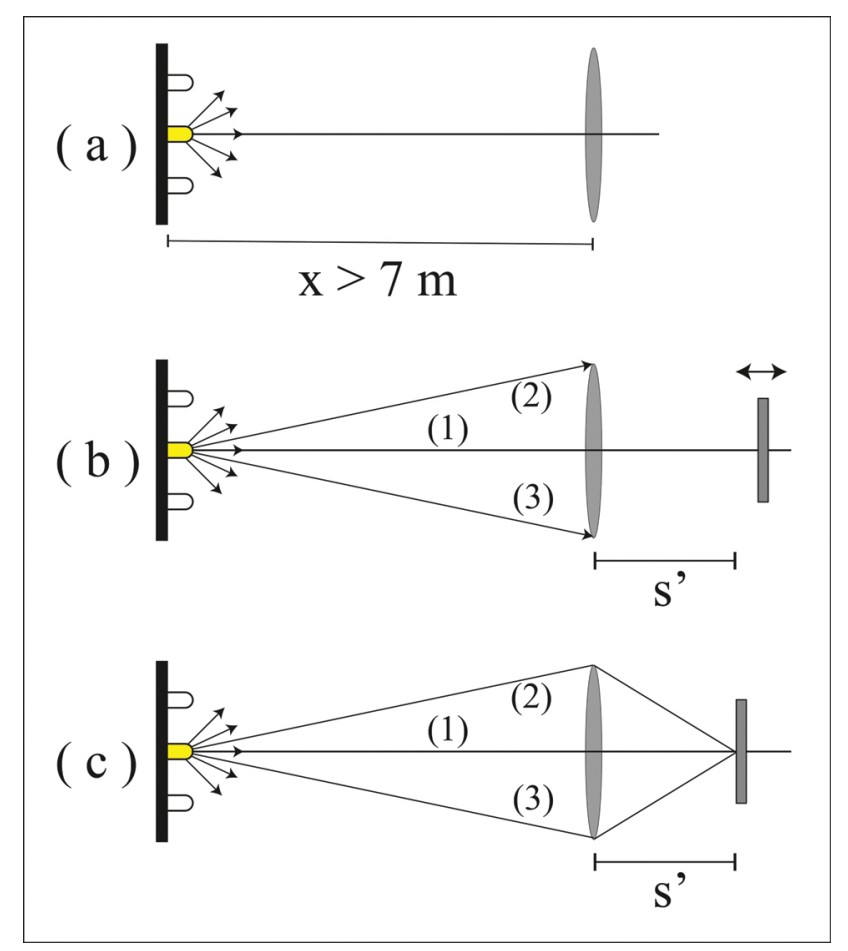

Figura 6: (a) $\mathrm{O}$ LED central $\left(\mathrm{L}_{2,2}\right)$ quando ligado emite luz dentro das condições de seu funcionamento. (b) Certa quantidade de luz emitida atravessa a lente. (c) A luz que atravessou a lente é direcionada para um ponto formando a imagem da fonte emissora (LED emissor). Observe que apesar da planificação do desenho esquemático no plano da folha do papel, deve-se imaginar um efeito tridimensional ocorrendo antes e depois da lente. Ou seja, em cada lado da lente imagina-se um cone de luz cuja base do cone é definida pela circunferência da lente.

Repare, na Figura 6c, que a imagem é formada apenas pela luz que foi emitida pelo LED e que se propagou através da lente.

Nesse ponto o que interessa é entender que com essa prática inicial conclui-se que existe um único raio de luz que sai da fonte iluminadora, se propaga através da lente, não é desviado pela lente e passará exatamente pelo plano de focalização da imagem. Como já definido, esse é o eixo óptico do sistema. Essa definição é importante porque as análises sempre serão realizadas em relação a esse eixo óptico ou a essa direção preferencial.

Pergunta-se: o que acontecerá se o LED superior for acionado? Vamos fazer isso olhando para a imagem do LED central projetada sobre a superfície do anteparo. Isso é, mantendo-se o LED central ligado, aciona-se o LED verde cuja cor aqui é indicada apenas por conveniência didática. Como resultado vê-se que a nova imagem formada, agora do LED verde, se forma exatamente no mesmo ponto em que se formou anteriormente a imagem do LED central. Quanto mais distante estiver a lente do iluminador melhor a superposição.

Preste atenção para os raios que estão indicados por linhas tracejadas na Figura 7a. Elas representam direções paralelas. 
( a )

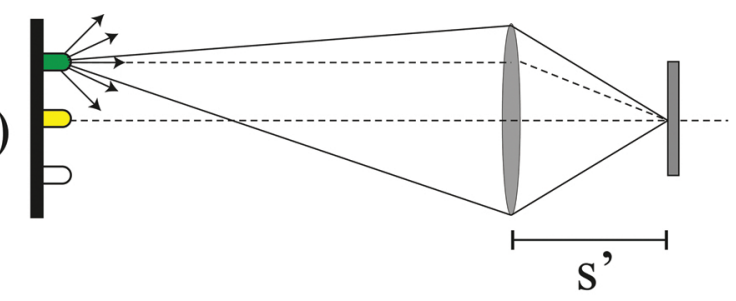

( b )

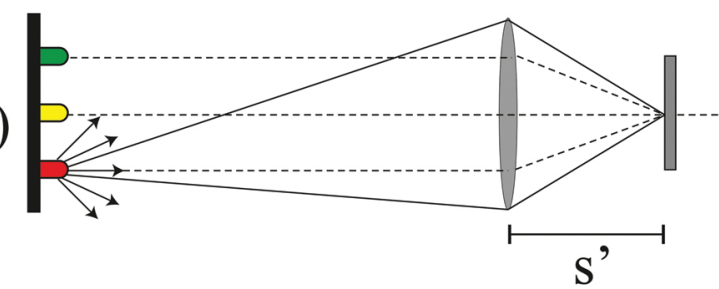

( c )

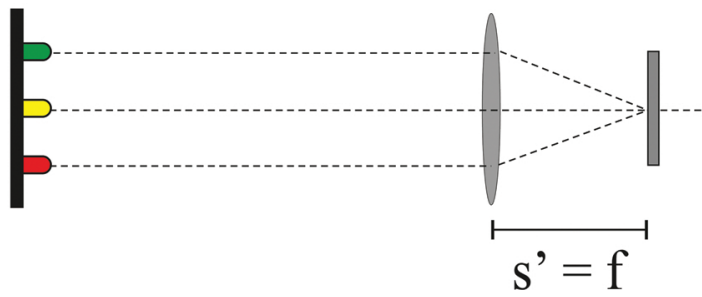

Figura 7: Uma continuação do processo apresentado na figura 6. (a) O LED superior da coluna do meio da composição foi ligado. A análise leva à conclusão de uma direção preferencial paralela ao eixo óptico. (b) O LED inferior foi ligado. Também se conclui que existe uma direção preferencial paralela ao eixo óptico. (c) A representação esquemática das conclusões anteriormente obtidas. Para cada LED existe uma direção paralela ao eixo óptico. Repare que essa é a representação apresentada nos livros didáticos.

O mesmo aconteceria ao acionarmos o LED inferior (vermelho por conveniência) (Figura 7b). Esse desenvolvimento experimental permite a representação realizada na Figura 6c. Esses são os raios que são traçados nos diagramas de estudos teóricos de óptica geométrica. Concluímos, portanto, que um feixe de raios paralelos ao eixo óptico quando incidente numa lente convergente, são direcionados para um mesmo ponto: o ponto focal. A representação da Figura 7 possui apenas os LEDs da coluna central $(\mathrm{n}=2)$. Tome cuidado porque essa figura é uma planificação de um efeito que possui características tridimensionais.

Na Figura 8 é mostrado um resultado obtido a partir do equipamento proposto em que todos os LEDs da composição estão ligados. Como essa imagem é formada? Na Figura 7 foi feita uma representação considerando apenas os três LEDs da coluna central. É uma representação planar na folha do papel. O mesmo esquema de visualização pode ser aplicado se olharmos para a direção da linha $\mathrm{m}=2$ ou mesmo se aplicarmos a visualização para as direções diagonais.

Na condição apresentada em que a distância entre o iluminador e a lente é infinita, a distância entre o vértice da lente e o plano de focalização de imagem é chamada de distância focal (f). Neste caso a distância focal (f) é coincidente à distância de focalização de imagem $\left(\mathrm{s}^{\prime}\right)$ da

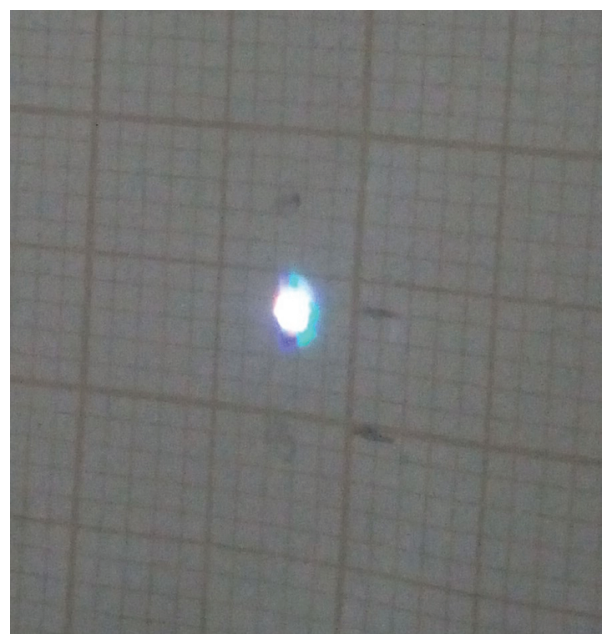

Figura 8: A imagem obtida com o iluminador (objeto) a uma distância maior do que $7 \mathrm{~m}$. Toda a energia luminosa que cruzou a lente é direcionada para um ponto de imagem no plano de imagem.

lente convergente utilizada. Agora meça essa distância pois ela será útil no futuro.

O próximo passo é aproximar a lente do iluminador para uma distância em torno de 0,5 m (uma distância de 4 a 5 vezes maior do que a distância focal). Para melhor resultado desligue todos os LEDs e repita o procedimento adotado para a distância de $7 \mathrm{~m}$. O resultado final é algo parecido àquele apresentado na Figura 9 (lembre-se que a dimensão lateral muda dependendo da distância de separação entre o iluminador e a lente).

Essa representação é importante porque distingue claramente a distância focal da lente do plano de focalização de imagem. Muitos pensam que essas distâncias são iguais, mas não são. A distância focal é uma propriedade da lente enquanto que o plano de imagem dependerá da

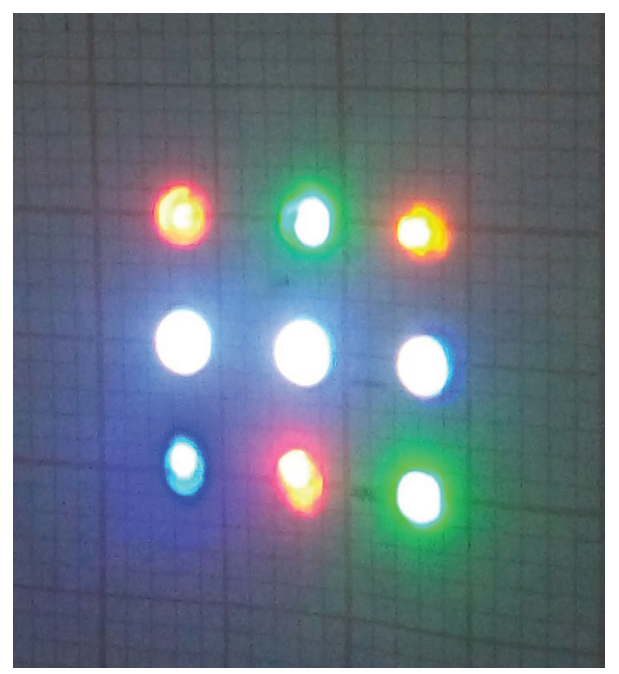

Figura 9: Uma imagem amplificada mostrando que o plano de imagem é diferente da distância focal da lente. 
distância existente entre o objeto a ser focalizado e a lente que irá produzir a imagem.

\subsection{Imagens reais}

Na Figura 10 é apresentado o esquema a ser utilizado como montagem básica. O iluminador, a lente convergente e o anteparo são alinhados nessa ordem. Na fotografia 10 é possível perceber que o registro fotográfico da montagem foi realizado com a iluminação ambiente acessa.

Vamos à prática. Inicialmente posicione a lente a uma distância entre 250 - $300 \mathrm{~mm}$ do iluminador. Essa distância garante que o objeto esteja posicionado fora da distância focal da lente que em nosso caso possui $\mathrm{f}=135$ $\mathrm{mm}$ e que foi a medida anteriormente registrada.

Liga-se o LED central e com o auxílio do anteparo procura-se a distância de focalização. Isso é feito movendose o anteparo até que a imagem do LED central, formada pela lente convergente, seja projetada sobre a superfície plana do anteparo. Nessa condição o sistema estará pronto para a atividade.

Em seguida, e enquanto se observa o que ocorre na superfície do anteparo, acenda o LED superior. Ao acionarse o LED superior verifica-se que ele teve sua imagem projetada para a parte inferior da imagem projetada no anteparo. Prossegue-se acendendo o LED inferior do iluminador. Agora, a imagem do LED é formada na parte superior do anteparo em relação ao eixo óptico. A cada LED individualmente ligado observa-se a imagem formada e qual posição ela se encontra em relação ao eixo óptico. Na Figura 11 é apresentada uma representação do resultado final dessa atividade.

A partir do resultado apresentado na Figura 11 duas conclusões podem ser obtidas: (1) a imagem que vemos é uma imagem real, ou seja, ela pode ser projetada porque possui energia luminosa incidindo sobre o anteparo no

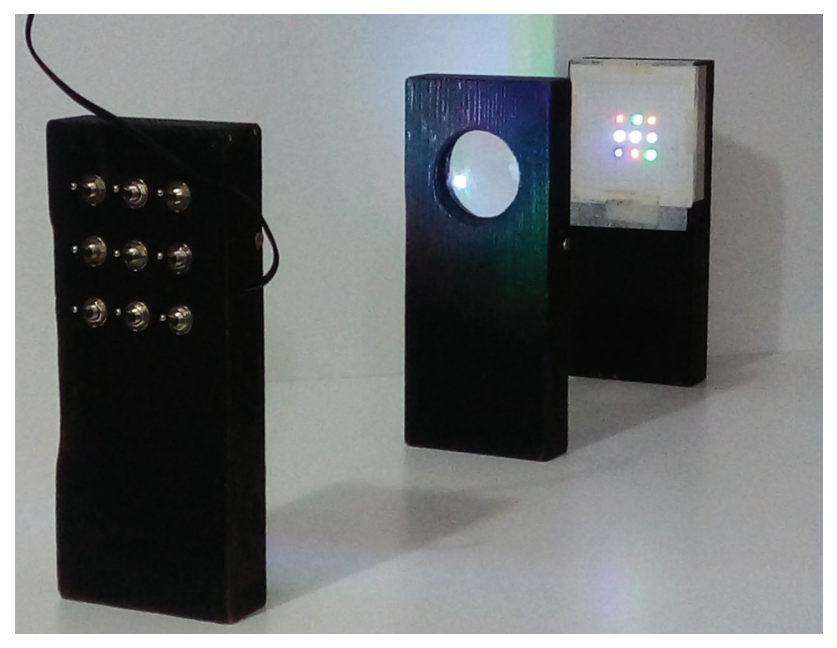

Figura 10: Uma fotografia da montagem básica utilizada em óptica geométrica para o estudo da formação de imagens por lentes convergentes.

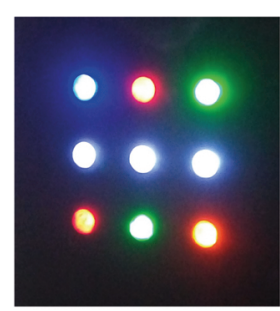

( a )

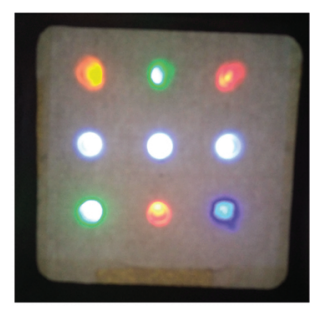

( b )
Figura 11: Uma fotografia do objeto e sua imagem formada pela lente convergente. (a) a condição final em que todos os LEDs do iluminador (objeto) estão ligados. (b) A imagem do objeto projetada sobre o anteparo. Para esse registro fotográfico foi utilizada a visão traseira do anteparo.

plano de imagem. (2) na condição apresentada na Figura 11, observamos a inversão de imagem produzida por uma lente convergente. O LED superior vermelho foi projetado para a posição inferior. O LED superior esquerdo (azul) apareceu na imagem com o LED inferior direito, e assim sucessivamente. Portanto, podemos definir que uma inversão de imagem como a rotação do objeto em torno da direção do eixo óptico por um ângulo de 180 graus. Diferentemente do que é apresentado nos livros didáticos aqui vemos o que ocorre tridimensionalmente. Estamos estudando um objeto extenso.

Nesse experimento aproveita-se a oportunidade para se discutir a aproximação de raios paraxiais. Os LEDs foram posicionados a distâncias simétricas em relação ao eixo óptico, na imagem é facilmente observável que os LEDs laterais possuem imagens distorcidas em relação a imagem do LED central.

Para continuar, afasta-se a lente do iluminador. Em seguida, repete-se o procedimento para recolocar o anteparo no novo ponto de focalização. Na Figura 12 é apresentado o resultado. A imagem ficou menor, entre-

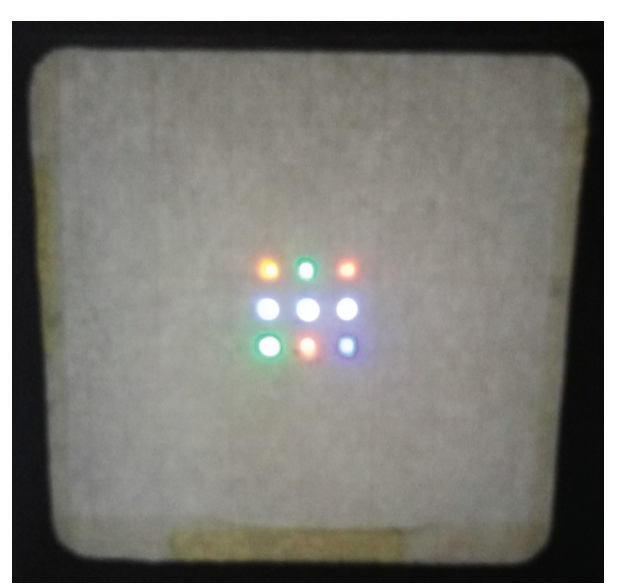

Figura 12: Uma fotografia do anteparo na nova condição em que a lente foi afastada do iluminador. Percebe-se que a imagem foi reduzida quando comparada a imagem apresentada na figura 11. 
tanto, continua real e invertida. E é o resultado esperado pois uma imagem real será sempre invertida.

Das Figuras 11 e 12 podemos identificar facilmente mais uma característica de uma imagem formada por uma lente convergente: a ampliação lateral de imagem. Nesse sentido poderíamos inclusive medir a distância entre os LEDs na imagem e calcularmos o valor da ampliação (equação 2). Isso porque sabemos que os LEDs foram simetricamente posicionados no iluminador com posições de $15 \mathrm{~mm}$ de distância entre si. Outra vantagem do iluminador é que ele permite perceber que a ampliação ocorre em todas as direções simultaneamente.

Finalizamos o estudo das imagens formadas por lentes convergentes na condição em que o objeto está posicionado fora da distância focal da lente. Ou seja, em condições em que a imagem é real e invertida.

\subsection{Imagem imprópria e virtual}

Uma das conclusões anteriormente apresentada foi a de que um feixe de raios paralelos ao eixo óptico incidindo sobre a lente é direcionado para o ponto focal. Faça-se o contrário. Posicionemos o iluminador no ponto focal. Como resultado tem-se um feixe de luz de raios colimados. Conclui-se que uma imagem imprópria é formada, ou seja, dizemos que uma imagem se formou no infinito. Para isso basta posicionarmos o iluminador a uma distância igual àquela medida no experimento do item a (distância focal).

O próximo passo é posicionar a lente a uma distância menor do que a distância focal da lente que está sendo utilizada. Em nosso caso, a distância deveria ser menor do que $135 \mathrm{~mm}$.

Nessa nova condição criaremos uma imagem virtual de nosso objeto. Na Figura 13 temos um registro dessa nova situação. Essa imagem está "dentro da lente", como se diz na linguagem cotidiana. Não há energia luminosa passando pela posição da imagem. Observa-se que a imagem possui a mesma direção e orientação do objeto. Ou seja, o LED superior vermelho no objeto aparecerá na parte superior, porém ampliado. O LED inferior verde aparecerá na parte inferior, porém ampliado, e assim sucessivamente. Conclui-se, portanto, que uma imagem virtual não pode ser projetada, é direita e ampliada. Novamente podemos introduzir as discussões sobre a aproximação de raios paraxiais.

\subsection{A inversão de imagem de um objeto simétrico}

Essa prática é bastante interessante porque realiza uma avaliação imediata do que foi discutido até o presente momento. Apesar da clareza dos fatos é de se notar a dificuldade dos alunos frente a essa nova situação. Essa prática é outra vantagem que vemos na utilização de nosso iluminador e que até onde sabemos não foi publicada até o momento e não é proposto por nenhum conjunto ótico comercializado no país. Aqui é importante dar a dica para

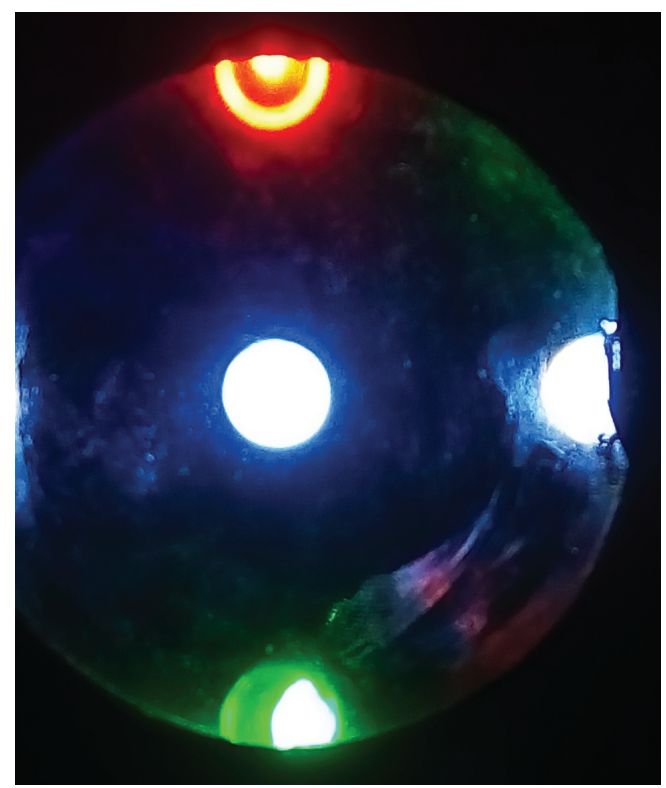

Figura 13: Um registro fotográfico de uma imagem virtual formada do iluminador na lente esférica convergente. Está-se olhando na direção da lente e através dela.

que a prática funcione. Ela somente pode ser realizada com a utilização do LED de cor branca. Isso porque no processo de fabricação, o LED recebe um recobrimento de um material que absorve a luz emitida pela junção e reemite como luz branca. Isso pode ser verificado olhandose para dentro do LED com ele desligado. Compare olhando para um LED de outra cor. Reveja a imagem do LED vermelho da Figura 13.

Anteriormente, tínhamos uma composição de LEDs simetricamente posicionados em relação ao LED central. Agora, o que se propõe é a formação da imagem do próprio LED central numa superfície distante. Na Figura 14a é apresentada a montagem de como obter essa condição. A lente esférica convergente é posicionada em frente ao iluminador apenas com o LED central ligado. Movimentase a lente até que a imagem do LED seja focalizada na superfície distante. Na Figura 14b temos uma visualização da imagem que será projetada. Repare que a imagem formada é um círculo luminoso.

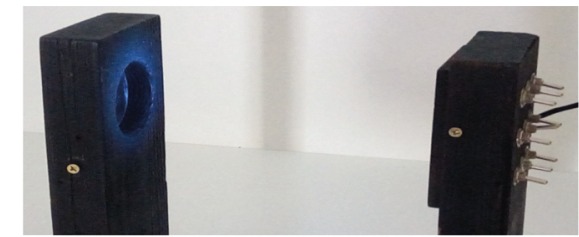

(a)

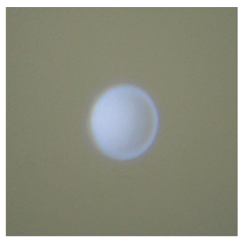

( b )
Figura 14: (a) Fotografia mostrando como é realizada a montagem para o estudo da inversão da imagem de um objeto simétrico. (b) A fotografia do objeto simétrico projetada sobre a superfície distante. 
Diante dessa constatação deve-se questionar: Aquela imagem formada é uma imagem invertida? Não se espante com o resultado pois a maioria dos estudantes poderá dizer que não. Ou ainda pior, poderão ficar calados. O que está sendo demonstrado aqui é que na prática do dia-a-dia não se entende qual é o verdadeiro significado de um objeto extenso. Restará ao professor provar que aquela imagem da Figura 14b é uma imagem invertida.

Para essa demonstração utiliza-se um pedaço de papel. Comece a encobrir lentamente o LED, no iluminador, de cima para baixo (Figura 15a). E em seguida, da esquerda para a direita (Figura 15c).

Os estudantes ficarão surpresos ao perceberem que enquanto a folha de papel começará a bloquear a luz do LED de cima para baixo a imagem projetada começará a desaparecer no sentido contrário (Figura 15b), ou seja, de baixo para cima ou da direita para a esquerda (Figura 15d), respectivamente.

Conclui-se que a imagem formada pela lente esférica convergente na condição ajustada é uma imagem real e invertida em relação ao objeto. Essa prática é importante justamente por que nos leva ao questionamento: Como poderíamos explicar que ao colocarmos um objeto simétrico extenso aparentemente são anulados os conhecimentos de inversão de imagem que acabamos de discutir?

\subsection{Determinando a distância focal da lente convergente - um método lúdico}

Basicamente duas formas são empregadas para a determinação da distância focal de uma lente delgada con-

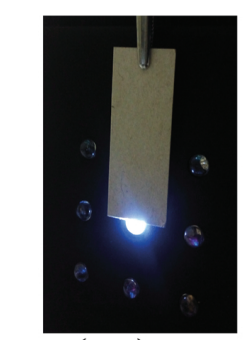

( a )

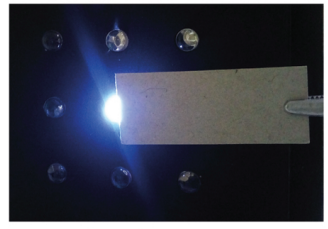

( c )

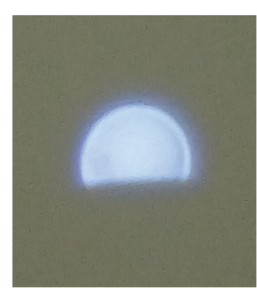

( b )

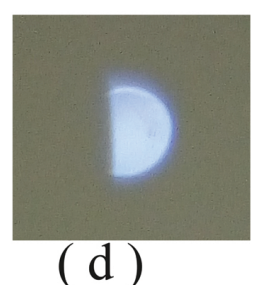

( d)
Figura 15: $O$ resultado da inversão de imagem de um objeto simétrico nas direções vertical e horizontal. A observação é feita olhando de frente para o iluminador. (a) Um pedaço de papel encobrindo o LED de cima para baixo. (b) A imagem desaparece de baixo para cima. (c) Um pedaço de papel encobrindo o LED da direita para a esquerda. (d) A imagem desaparece da esquerda para a direita. vergente. Ambas podem ser facilmente justificadas pela análise da equação 1. Na primeira, fazemos uma medida direta da distância focal (Ver Figura 7c). Para isso, aumenta-se infinitamente a distância entre o objeto e a lente e facilmente se verifica que nessa condição teremos $\mathrm{f}=\mathrm{s}$. Na segunda, posiciona-se o objeto a uma certa distância da lente e medem-se as distâncias s e s' (método utilizado em bancos óticos). Através da equação 1 obtém-se indiretamente a distância focal. Nesse caso, várias medidas para valores diferentes de s são realizadas para se verificar que o resultado de f se mantém.

Nesse item queremos demostrar uma maneira bastante lúdica de determinação direta da distância focal, mas que secundariamente permite uma averiguação dos conceitos anteriormente estudados.

Para isso desenvolve-se o experimento com base naquele utilizado na Figura 10. Uma lente convergente é posicionada acerca de $250 \mathrm{~mm}$ de distância do iluminador. Na lente são fixados pequenos obstáculos circulares: um no centro da lente e outros dois simetricamente posicionados um acima e o outro abaixo do obstáculo central (a separação é a mesma da separação entre os LEDs) (Figura 16a). Em seguida, aciona-se apenas o LED central. Com isso, três sombras serão projetadas no anteparo posicionado acerca de $100 \mathrm{~mm}$ da lente (Figura 16a). Observe que as três sombras foram identificadas pelos números 1 (central), 2 (superior) e 3 (inferior), respectivamente. Feito isso, vamos desligar o LED central e acionar o LED superior vermelho. Como resultado verifica-se que as sombras não coincidem com as marcações anteriormente realizadas, mas todas aparecem abaixo destas (Figura $16 \mathrm{~b})$.

O mesmo pode e deve ser feito para o LED inferior. Desliga-se o LED superior e aciona-se apenas o LED inferior (Figura 16c). Repare que novamente não existem coincidências. Agora as sombras aprecem acima das marcações realizadas na etapa inicial. Na Figura 16d verifica-se que ao mantermos ligados ambos os LEDs, superior e inferior, a marcação no anteparo não fica coincidente com nenhuma das sombras. Vamos então ao "pulo

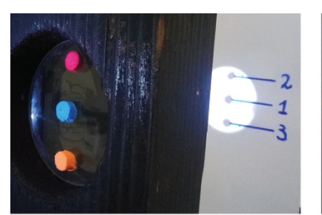

( a )

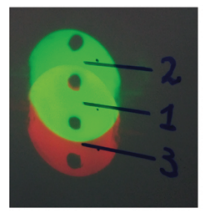

(d)

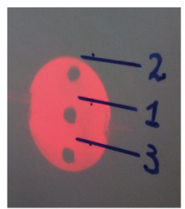

( b )

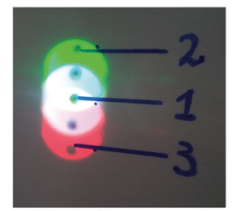

( e )

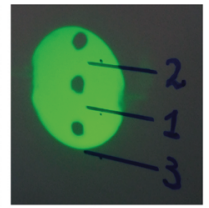

( c )

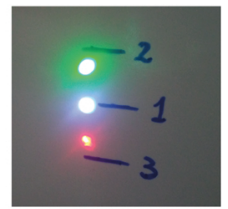

( f)
Figura 16: As etapas que devem ser observadas para a determinação da distância focal pelo método aqui proposto. 
do gato". Comece a afastar o anteparo lentamente da lente. Você verificará que num certo ponto duas sombras serão coincidentes exatamente com a marcação central identificada pelo número 1 (Figura 16e). Essa distância do anteparo até a lente é a distância focal. Por quê? Se você não reparou verifique que a coincidência que apareceu foi entre a sombra superior do LED vermelho com a sombra inferior produzida pelo LED verde. Para entender compare esse resultado com o desenho esquemático da Figura 7c. Imagine que o que se produz normalmente com um feixe de luz agora está se produzindo com a falta dele.

Uma variação para a confirmação do resultado é desligar os LEDs e acioná-los um a um enquanto se observa a projeção da sombra sobre o anteparo. Concluímos que essa distância do anteparo até a lente é a distância focal. Observe que a imagem ainda não está nítida. Continue então afastando o anteparo da lente. Um pouco mais adiante você verificará que a imagem será formada. Esse é o plano de imagem em que a imagem se torna nítida (Figura 16f). Por fim vale ressaltar que a imagem projetada sobre a tela do anteparo é uma imagem real, invertida e menor, como pode ser verificado na Figura $16 \mathrm{f}$.

\section{Conclusões}

Apresentamos nesse trabalho a descrição de um iluminador para ser utilizado como fonte luminosa para experimentos de óptica geométrica de lentes e espelhos. O equipamento desenvolvido, quando comparado aos equipamentos comerciais, apresenta algumas vantagens que são enumeradas:

- O iluminador desenvolvido é uma composição de LEDs de alta intensidade. Essa composição permite que os trabalhos de óptica geométrica possam ser executados sem a necessidade de escurecimento do ambiente de trabalho.

- O iluminador permite o acionamento individualizado de cada um dos LEDs que o compõe. Essa característica permite o estudo ponto a ponto na inversão de imagens formadas por lentes esféricas.

- O equipamento desenvolvido possui como característica a possibilidade de simulação de uma superfície refletora de luz.

- Por ser produzido em base mecânica retangular o iluminador pode ser posicionado diretamente sobre a mesa de trabalho. Com essa característica mecânica o conjunto ótico desenvolvido permite que façamos experimentos livremente sobre a bancada sem ficarmos presos e limitados a um banco óptico dimensionado pelo fabricante.

- O iluminador não possui elemento óptico para criar um feixe colimado. Os elementos que o compõem são previamente posicionados em simetria permitindo uma fácil utilização no estudo de dimensionamento de imagens.
- Com esse equipamento desenvolvido é possível o estudo de inversão de imagem de elementos simétricos.

- Outra vantagem é a facilidade no estudo de imagens virtuais. Esse iluminador permite uma fácil compreensão desta característica importante presente nesses elementos ópticos.

- O iluminador auxilia no entendimento da formação de imagens de forma real porque simula pontos emissores de luz em várias direções.

- O iluminador permite também demonstrar o caminho óptico percorrido por um feixe de luz paralelo ao eixo óptico do sistema. Esse mesmo experimento permite a determinação por medida direta da distância focal da lente convergente utilizada.

- O conjunto apresentado permite quebrarmos um paradigma de que para a realização de experimentos de ótica é necessário possuirmos um banco ótico.

\section{Agradecimentos}

Os autores agradecem ao LAUS-DEFIS-UEPG pela confecção dos elementos utilizados nesse trabalho.

\section{Referências}

[1] D Soga, R.D. Paiva Jr. e M. Muramatsu, Rev. Bras. Ensino Fís. 39, e3506 (2017).

[2] W.L. Almeida, F.M.M. Luz, J.B. Silva, S.L.R. Silva e A.M. Brinatti, Cad. Bras. Ens. Fís. 30, 396 (2013).

[3] C.E. Aguiar, Rev. Bras. Ensino Fís. 31, 3302 (2009).

[4] F.L. Silveira e R. Axt, Rev. Bras. Ensino Fís. 28, 425 (2006).

[5] N. Carlin, E.M. Szanto, F.O. Jorge, F.A. Souza, I.H. Bechtold e W.A. Seale, Rev. Bras. Ensino Fís. 29, 304 (2007).

[6] https://www.educarecompanhia.com/kit-fsicaoptica, acessado em 05/06/2017.

[7] http://www.hexasystems.com.br/produto, acessado em 05/06/2017.

[8] http://www.rlink.com.br/index.php/vendorcontact/kits-educacionais, acessado em 05/06/2017.

[9] https://www.pasco.com/filters/topics acessado em 05/06/2017.

[10] http://www.maxwell.ind.br/produtos, acessado em $05 / 06 / 2017$

[11] http://www.cidepe.com.br/index.php/br/produtos acessado em 05/06/2017.

[12] https://azeheb.com.br/ensino-medio/fisica/ otica, acessado em 05/06/2017.

[13] http://www.lojadoprofessor.com.br/equipamentospara-abotatorio/conjunto-de-optica.html, acessado em 05/06/2017. 